\title{
Hypoplastic left heart with complete transposition of the great arteries
}

\author{
DIETER LANG , * ROLAND HOFSTETTER,† CHRISTOPH KUPFERSCHMID*

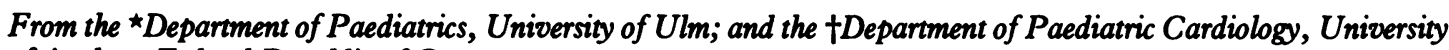 \\ of Aachen, Federal Republic of Germany
}

SUMMARY A male newborn infant with hypoplastic left heart and transposition of the great arteries died on the second day of life. The haemodynamic consequences of this malformation are considerably different from those of ordinary hypoplastic left heart syndrome because of pulmonary rather than aortic atresia. In the absence of cross sectional echocardiographic equipment, cardiac catheterisation with angiography is necessary to delineate the anatomical picture. These two conditions have not apparently been reported before in association.

Hypoplastic left heart syndrome is defined clinically as severe underdevelopment of the left ventricle and atresia of the aortic or the mitral valve or both. ${ }^{1}$ The incidence of this malformation accounted for $1.5 \%$ of 15105 cases of congenital heart defects. ${ }^{2}$ To our knowledge hypoplastic left heart syndrome in combination with complete transposition of the great arteries has not been previously reported. ${ }^{23} \mathrm{We}$ report a male infant with this malformation.

\section{Case report}

A male infant was born after an uneventful pregnancy and delivery (birth weight $3.81 \mathrm{~kg}$ ). He was transferred to our hospital several hours after birth because of progressive cyanosis and tachypnoea. Physical examination also showed a slightly accentuated precordial impulse and a normal first and a single second heart sound. A short systolic murmur (grade 2/6) was heard along the left sternal edge. The liver edge was palpable $3 \mathrm{~cm}$ below the right costal margin, and the brachial and femoral artery pulses were normal.

\section{INVESTIGATIONS}

The electrocardiogram showed right axis deviation and right ventricular hypertrophy with a net negative deflection over the left precordium. The chest radio-

Requests for reprints to Dr Dieter Lang, Universitäts-Kinderklinik, Prittwitzstrasse 43, D-7900 Ulm, FRG. graph showed an enlarged heart and reduced pulmonary vasculature. The liver was on the right and the stomach on the left side.

Echocardiography-The $M$ mode echocardiogram (Fig. 1a) showed hypoplasia of the posterior (left) ventricle (left ventricular end diastolic dimension $<10$ $\mathrm{mm}$ ), a hypoplastic posterior (mitral) atrioventricular valve, an enlarged anterior (tricuspid) atrioventricular valve, and an enlarged anterior (right) ventricle. There was also a large anterior vessel arising from the anterior ventricle and a small posterior vessel overriding the ventricular septum but without access to either of the two ventricles. The suprasternal notch view indicated that the hypoplastic vessel was the pulmonary artery. This interpretation was confirmed subsequently by cardiac catheterisation and angiography.

Haemodynamic data-There was systemic pressure in the right ventricle and no gradient to the ascending aorta (Table). The oxygen saturation percentages indicated an interatrial left to right shunt.

Angiography of the left atrium, right ventricle, and the ascending aorta showed a small left atrium and an intense backflow of contrast medium into the pulmonary veins. The left ventricle was not opacified (Fig. 1b). Instead the contrast medium passed from the left to the right atrium and hence into the right ventricle, from which opacification of the anteriorly placed ascending aorta occurred. A hypoplastic pulmonary artery was filled from the distal aortic arch through a 


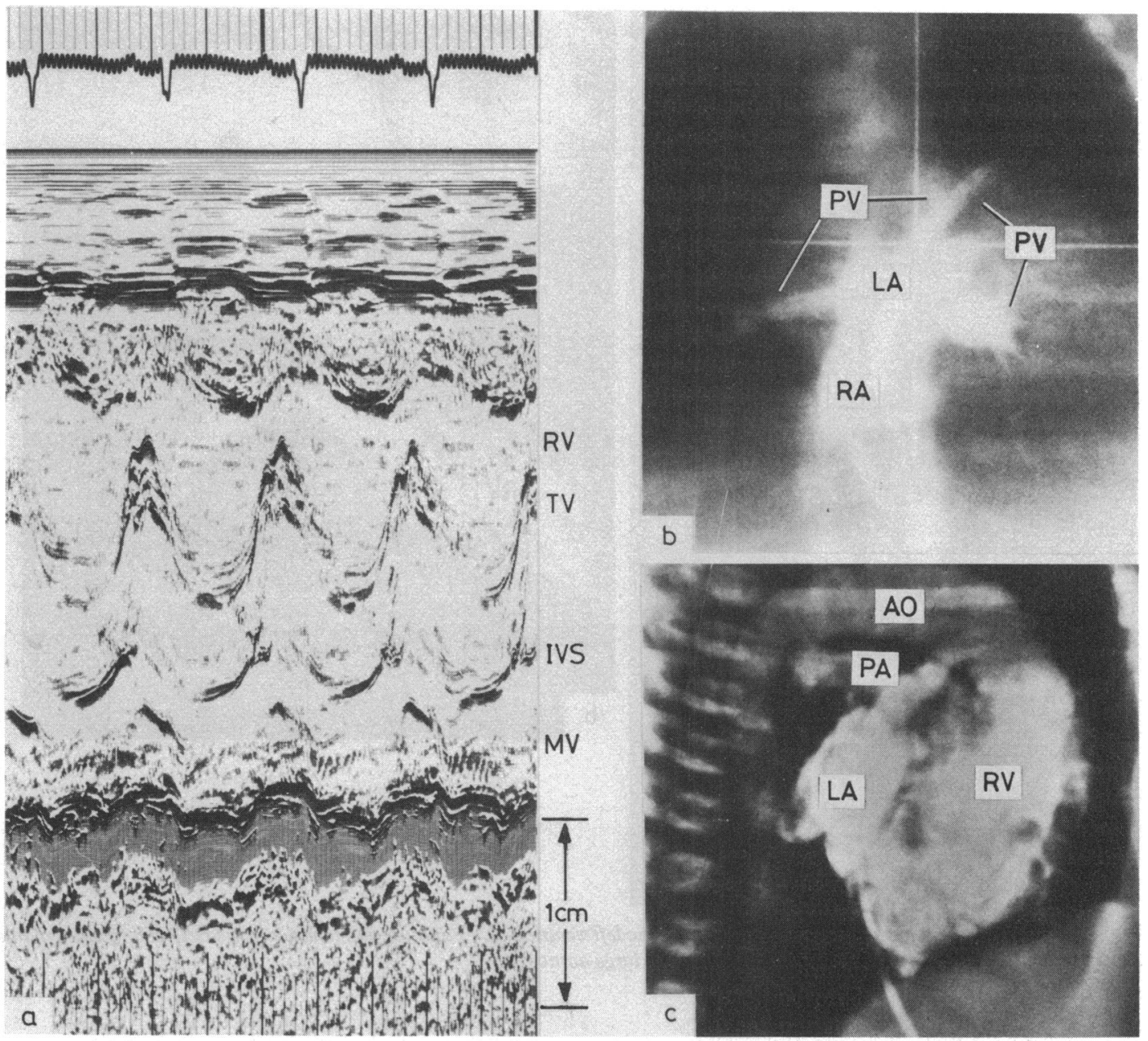

Fig. 1 (a) M mode echocardiogram in parasternal view showing hypoplasia of the posterior (left) ventricle (left ventricular end diastolic dimension $<10 \mathrm{~mm}$ ), a hypoplastic posterior (mitral) valve (MV), and an enlarged anterior (right) ventricle $(R V)$ and tricuspid valve (TV). IVS, interventricular septum. (b) Left atrial angiogram in the anteroposterior view showing filling of the left atrium $(L A)$ and the pulmonary veins $(P V)$ and refux of contrast media into the right atrium $(R A)$; there was no opacification of a left ventricle. (c) Left atrial angiogram in the lateral projection showing opacification of the left atrium $(L A)$, filling of the right ventricle $(R V)$ by a left to right interatrial shunt, and a discordantly connected aorta $(A O)$. Opacification of the hypoplastic posterior pulmonary artery $(P A)$ occurred via a persistent ductus arteriosus.

small ductus arteriosus (Fig. 1c).

Diagnosis-Situs solitus with atrioventricular concordance and ventriculoarterial discordance (complete transposition of the great arteries), atresia of the mitral (imperforate valve) and pulmonary valves, hypoplasia of the left ventricle, and a patent foramen ovale were diagnosed.

Necropsy-The patient died on the second day of life. The diagnosis was confirmed at necropsy. The left atrioventricular valve was imperforate and the valve annulus small. The left ventricle was a slit like
Table Haemodynamic data

\begin{tabular}{|c|c|c|}
\hline Site & $\begin{array}{l}\text { Pressure (mean) } \\
\left(m m H_{g}\right)\end{array}$ & $\begin{array}{l}\text { Oxygen saturation } \\
(\%)\end{array}$ \\
\hline $\begin{array}{l}\text { Superior vena cava } \\
\text { Mid right atrium } \\
\text { Inferior vena cava } \\
\text { Right ventricle } \\
\text { Ascending aorta } \\
\text { Left atrium }\end{array}$ & $\begin{array}{l}\overline{7} / 0(1) \\
\overline{80} / 0(10) \\
80 / 50(63) \\
11 / 0(2 \cdot 5)\end{array}$ & $\begin{array}{l}30 \\
43 \\
36 \cdot 5 \\
40 \\
42 \\
95\end{array}$ \\
\hline
\end{tabular}

Systemic blood flow $8.3 \mathrm{l} / \mathrm{min} \mathrm{m}^{2}$.

Pulmonary blood flow $1.2 \mathrm{l} / \mathrm{min} \mathrm{m}^{2}$.

Effective pulmonary blood flow $=1.11 \mathrm{~min} \mathrm{~m}^{2}$. 

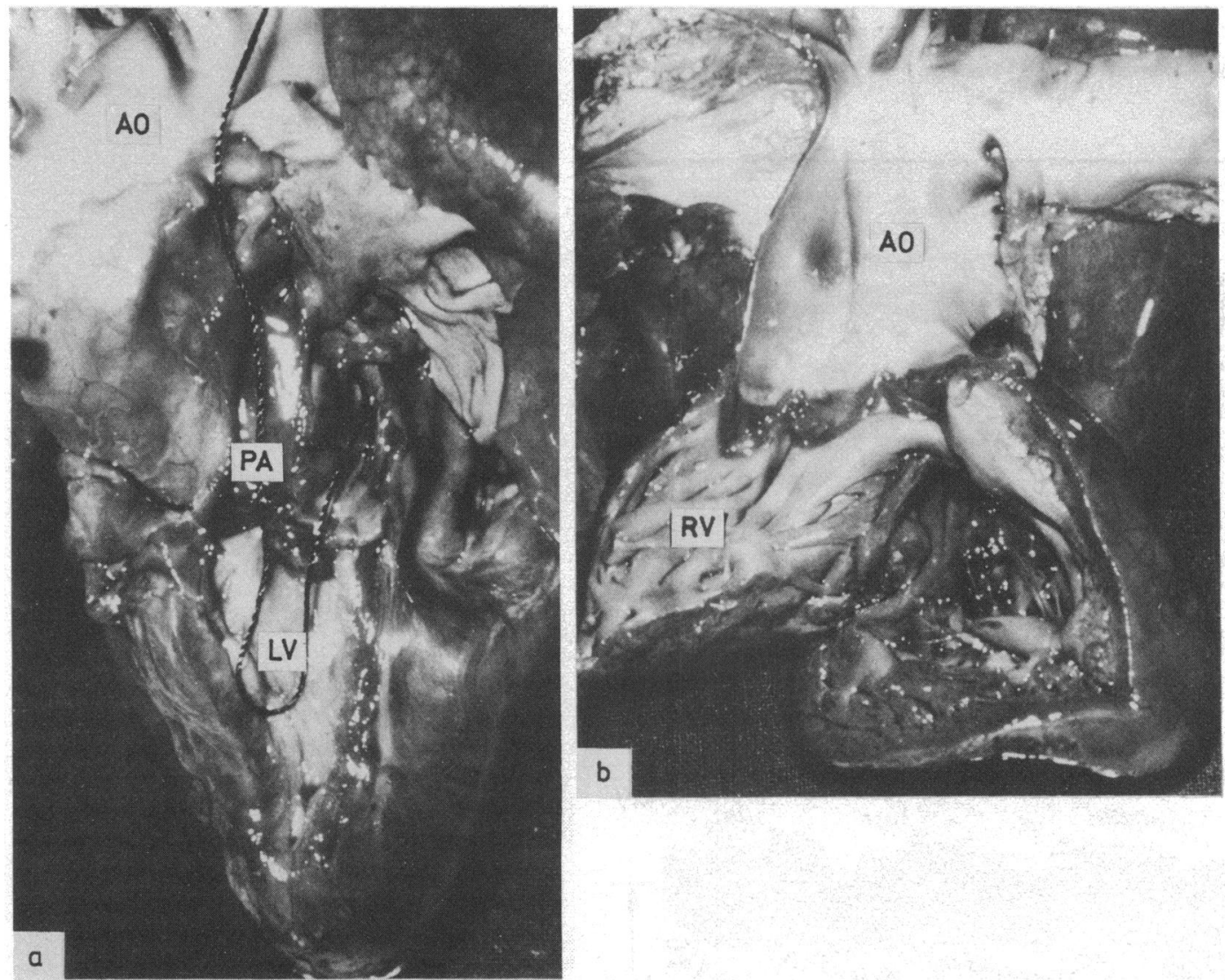

Fig. 2 Morphological appearance of (a) the hypoplastic left ventricle $(L V)$ and the pulmonary artery $(P A)$ and $(b)$ the enlarged grossly trabeculated right ventricle $(R V)$ giving rise to a large aortic root.

chamber, which showed a typical left ventricular morphology with smooth trabeculation. There was no endocardial fibroelastosis (Fig. 2a). The pulmonary valve consisted of three leaflets which were fused at their commissures, thus forming an imperforate valve. The valve ring and the pulmonary trunk were hypoplastic up to the bifurcation. The right ventricle was enlarged and showed gross trabeculation. The wide aortic root was connected to a non-restrictive right ventricular infundibulum, and the aortic valve leaflets were tricuspid and not stenotic (Fig. 2b). The right coronary artery originated from the posterior sinus and the left from the left sinus of the aortic valve. The foramen ovale was patent and the ductus arteriosus persisted. No other associated anomalies were found.

\section{Discussion}

To our knowledge hypoplastic left heart syndrome with transposition of the great arteries has not previously been reported..$^{23}$ One case of aortic artresia in association with complete transposition of the great arteries but without hypoplastic left ventricle and mitrel atresia has been reported. ${ }^{4}$ Transposition, ventricular septal defect, and severe pulmonary stenosis or atresia occur in about $5 \%$ of neonates with transposition. ${ }^{5}$

The haemodynamic consequences of this malformation are considerably different from those of the ordinary hypoplastic left heart syndrome with regard to the blood supply to the systemic and the pulmonary circulations. The physiology, of course, is also different from that in simple transposition of the great arteries and resembles that in univentricular heart with pulmonary atresia. The physical and radiographic findings (normal pulses and diminished pulmonary vasculature) do not therefore suggest hypoplastic left heart syndrome. The electrocardiogram and the $M$ mode echocardiogram may indicate left 
heart hypoplasia but are not reliable in detecting ventriculoarterial discordance. With echocardiography, however, an imperforate atrioventricular valve may be differentiated from an absent connection. ${ }^{6}$ With cross sectional echocardiography a correct diagnosis may also be established without major difficulty. In the absence of cross sectional echocardiographic equipment, cardiac catheterisation with angiocardiography is necessary to delineate the anatomical picture.

\section{References}

1 Lev M. Pathologic anatomy and interrelationship of hypoplasia of the aortic tract complexes. Lab Invest 1952; 1: $61-70$.
2 Freedom RM. Aortic atresia. In: Keith JD, Rowe RD, Vlad $P$, eds. Heart disease in infancy and childhood. New York: Macmillan, 1978: 542-48.

3 Thiene G, Daliento L, Frescura C, De Tommasi M, Macartney FJ, Anderson RH. Atresia of left atrioventricular orifice. Anatomical investigation in 62 cases. $\mathrm{Br}$ Heart f 1981; 45: 393-401.

4 McGarry KM, Taylor JFN, Macartney FJ. Aortic atresia occurring with complete transposition of great arteries. Br Heart F 1980; 44: 711-13.

5 Paul MA. D-transposition of the great arteries. In: Moss AJ, Adams FH, Emmanoulides GC, eds. Heart disease in infants, children and adolescents. 2nd ed. Baltimore: Williams and Wilkins, 1977: 301-38.

6 Shore D, Jones O, Rigby ML, Anderson RH, Lincoln C. Atresia of left atrioventricular connection. Surgical considerations. Br Heart f 1982; 47: 35-40. 